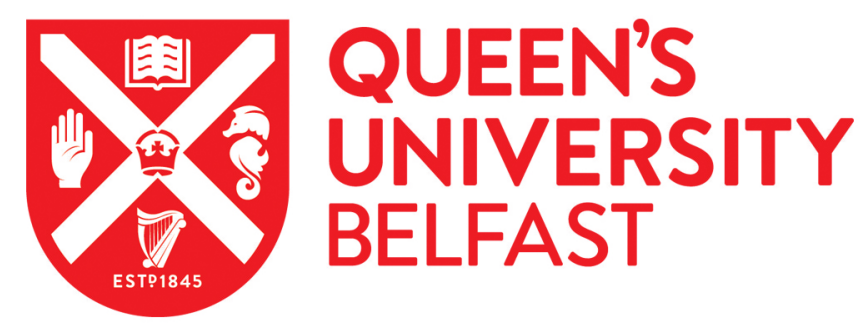

\title{
Reporting Harm in Glaucoma Surgical Trials: Systematic Review and a Consensus Derived New Classification System
}

Sii, S., Barton, K., Pasquale, L. R., Yamamoto, T., King, A. J., \& Azuara-Blanco, A. (2018). Reporting Harm in Glaucoma Surgical Trials: Systematic Review and a Consensus Derived New Classification System. American Journal of Ophthalmology, 153-162. https://doi.org/10.1016/j.ajo.2018.07.014

Published in:

American Journal of Ophthalmology

Document Version:

Peer reviewed version

Queen's University Belfast - Research Portal:

Link to publication record in Queen's University Belfast Research Portal

Publisher rights

(c) 2018 Crown Copyright.

This work is made available online in accordance with the publisher's policies. Please refer to any applicable terms of use of the publisher.

\section{General rights}

Copyright for the publications made accessible via the Queen's University Belfast Research Portal is retained by the author(s) and / or other copyright owners and it is a condition of accessing these publications that users recognise and abide by the legal requirements associated with these rights.

Take down policy

The Research Portal is Queen's institutional repository that provides access to Queen's research output. Every effort has been made to ensure that content in the Research Portal does not infringe any person's rights, or applicable UK laws. If you discover content in the Research Portal that you believe breaches copyright or violates any law, please contact openaccess@qub.ac.uk. 


\section{Title Page}

\section{Title: Reporting Harm in Glaucoma Surgical Trials: Systematic Review and a Consensus Derived New Classification System}

Short Title: Reporting Harm in Glaucoma Surgical Trials

\section{Authors}

Samantha Sii, MD, ${ }^{1}$ Barton K, FRCOphth, ${ }^{2}$ Pasquale LR, MD, FARVO, ${ }^{3}$ Yamamoto T, MD, PhD, ${ }^{4}$ King A, FRCOphth, ${ }^{5}$ Azuara-Blanco A, PhD, FRCOphth, ${ }^{6}$

\footnotetext{
${ }^{1}$ Belfast Health and Social Care Trust, UK

${ }^{2}$ Glaucoma Service, Moorfields Eye Hospital, London EC1V 2PD, United Kingdom. UCL Institute of Ophthalmology, Bath Street, London, United Kingdom.

${ }^{3}$ Department of Ophthalmology, Department of Ophthalmology, Harvard Medical School, Boston, MA, USA.

${ }^{4}$ Department of Ophthalmology, Gifu University Graduate School of Medicine, Gifushi, Japan

${ }^{5}$ Department of Ophthalmology, Nottingham University Hospital, Nottingham, NG7 $2 \mathrm{UH}, \mathrm{UK}$

${ }^{6}$ Centre for Public Health, Queen's University Belfast, UK
}

Corresponding author details:

Name: Augusto Azuara-Blanco

Address: ICS-A, Grosvenor Road, Belfast, BT12 6BA, UK

Phone number: 442890635009

Fax number: 442890235900

E-mail address: a.azuara-blanco@qub.ac.uk 


\section{INTRODUCTION}

With improving technology, new types of glaucoma surgery are emerging, though conventional procedures such as trabeculectomy and aqueous shunts remain commonly undertaken procedures. Glaucoma surgery is usually offered to patients with disease progression, uncontrolled intraocular pressure (IOP) on maximum tolerable medical therapy, patients with advanced disease at presentation or as an alternative to drops. $^{1-4}$

When comparing surgical interventions using randomized controlled trials (RCTs), evaluation of safety is as important as efficacy. Capturing and quantifying harm resulting from surgery is expected ${ }^{5}$ though the reporting of complications from interventions lack uniformity and quality across several medical specialties. ${ }^{5-8}$

The World Glaucoma Association (WGA) has outlined key recommendations for reporting glaucoma surgical trial results including a comprehensive list of complications. ${ }^{9}$ However there has not been an attempt to quantify harm or reach a consensus regarding the severity of each complication. In contrast, clinical trials of general surgery and urology typically use a standardized classification of severity to quantify degree of surgical harm. ${ }^{5-8}$

The purpose of our study is firstly, to assess the quality of harm reporting among contemporary RCTs published since 2010 using the Consolidated Standards of Reporting Trials (CONSORT) extension for harm as a benchmark. ${ }^{10}$ Secondly, we aim to establish a severity score for recognized complications of glaucoma surgery through a consensus approach among glaucoma experts to generate a classification system of severity of glaucoma surgical complications

\section{METHODS}

This project has a twofold component, a systematic review of the literature and a Delphi survey among glaucoma experts. In line with the central tenet of the Declaration of Helsinki, all the survey participants gave their informed consent. Formal ethical review board approval was not sought. We conducted a systematic review and searched for 
RCTs of glaucoma surgical interventions. Trials eligible for inclusion were those reporting outcomes of trabeculectomy and aqueous shunts published or registered from January 2010 to July 2017. We excluded trials of laser treatments and those evaluating novel techniques such as minimally invasive glaucoma surgery (MIGS), registered trials that have not published data, trials involving children, publications that were not in English and trials on interventions to manage complications arising from glaucoma surgery. The protocol of the systematic review was registered in PROSPERO (https://www.crd.york.ac.uk/prospero/): CRD42017079778. A detailed description of the search strategy is available in Appendix 1. Two reviewers (SS, AA-B) independently reviewed the titles and abstracts to identify eligible studies. For abstracts that were either potentially eligible or ambiguous, full text articles were sourced and reviewed to determine eligibility (Figure 1) and extract data.

For those eligible publications we utilized the CONSORT extension for harm to evaluate the quality of reporting of complications. The CONSORT harm checklist is an extension of the original CONSORT 22 item checklist ${ }^{10}$ that includes 10 broad criteria with additional descriptors. (Table 1). We adopted the approach previously used for reviewing harm reporting based on the CONSORT harm checklist in surgical trials ${ }^{11}$ but excluded one item, "description of adverse events leading to death", as this is not expected to happen after glaucoma surgery. We assigned a yes $(\checkmark)$, no $(x)$ or (N/A) to each of the 15 items listed (Appendix 2, Supplemental Material at AJO.com). Data collected was represented as a percentage of studies complying with each criterion (Table 1). All the articles were independently reviewed by two reviewers (SS, AA-B) and any disagreements were resolved with discussion between the two reviewers.

A Delphi method was employed to reach a consensus among experts on the severity of glaucoma complications. The Delphi method is an iterative consensus technique, which comprises presentation of sequential questionnaires, which are answered anonymously by a panel of participants with relevant expertise. Questioning takes place over two or more rounds, and after each round of questions a summary of the responses is fed back to the expert group. Respondents may then use this additional information to modify their original answers or to change their opinion in the subsequent round of 
voting. In general with each round the range of answers for an individual question decreases and the group converge towards a consensus opinion. We approached representatives of the European Glaucoma Society, American Glaucoma Society, Japanese Glaucoma Society, Asia-Pacific Glaucoma Society, and International Society of Glaucoma Surgery, and ophthalmologists with experience in glaucoma clinical trials from these societies were invited to participate in the Delphi exercise $(n=43)$. Prior to undertaking the Delphi exercise we conducted a pilot phase to refine the survey content and test the software platform (Appendix 1, Supplemental Material at AJO.com). In the Delphi exercise we presented general complications of glaucoma surgery, and specific complications of trabeculectomy and aqueous shunts. For each complication we provided instructions for the clinician to grade severity from 1 to 10 , where 1 indicates "no harm" and 10, the worst possible surgical outcome (e.g., permanent total visual loss and painful eye). In round 1 of the Delphi survey, a space was provided under each question for the clinician to provide any relevant comments. Enalyzer PRO (Copenhagen, Denmark) software was utilized as a platform for the Delphi survey. Round 1 survey questions can be accessed on https://surveys.enalyzer.com?pid=g8s8m5pa Amendments were made after taking into consideration comments from round 1 . The finalized list of questions in round 2 can be accessed on https://surveys.enalyzer.com?pid=m5hm5r57. Responses gathered were collected into an excel sheet. The median grade and interquartile range for the severity of each complication was calculated. An interquartile range (IQR) of $\leq 2$ in severity classification was considered necessary for reaching consensus. (Figures 2, 3, 4, Supplemental Material at AJO.com)

\section{RESULTS}

Our search initially yielded 101 titles and abstracts. A total of 47 studies were deemed eligible (Figure 1). Among the eligible studies, one study ${ }^{61}$ did not report any complications, one study was published in letter to editor format ${ }^{53}$, one is a registered trial which is not published ${ }^{14}$ and three are baseline studies of large RCTs without long 
term complication data. ${ }^{26,28,30}$ The full list of excluded articles is attached in appendix 1. There were 15 publications with trials involving trabeculectomy, 14 involving aqueous shunts, seven involving trabeculectomy in combination with Express shunt or canaloplasty, six involving phaco-trabeculectomy, three involving aqueous shunts in combination with other methods, one comparing trabeculectomy, sclerectomy, Ahmed valve and Express shunt; and one comparing canaloplasty and non-penetrating deep sclerectomy.

We assessed the number of studies fulfilling the 10 criteria in CONSORT extension for harm checklist from a total of 47 trials (Table 1). None of the eligible studies used a validated instrument to report severity of adverse events. Only one study specified withdrawals due to harm. ${ }^{49}$ Other criteria that were infrequently reported included subgroup analyses for harm (6.4\%), withdrawals due to harm (6.4\%), attribution of methods to harms (10.6\%), absolute risk of harm in appropriate metrics and variables $(14.9 \%)$, reporting severity of adverse events (21.3\%), definitions used for analysis of harm $(21.3 \%)$ and analysis of harm (25.5\%). Among studies which reported definitions of adverse events (34\%), three trials reported use of a list of expected adverse events and facilitated reporting of unexpected events in their trial data collection sheets with additional space 1,2,3,15,26,27,28,52; whilst three trials included their own predefined list of complications. ${ }^{26,34,49}$ The remaining publications did not address how they defined complications.

In reporting the severity of adverse events, two large multicenter trials defined sight threatening complications as loss of at least 2 lines of Snellen VA or return to the operating room. 1,2,3,26,27,28 Five studies provided definitions of major, devastating or severe complications in their methodology $1,2,3,26,27,28,34,45,48$ or attempted to give examples of them ${ }^{16,17}$. The different descriptions of severe or major complications are detailed in Table 2.

Forty-three glaucoma experts were invited to participate in the Delphi survey. Of the invited participants, 41 (95\%) took part in the round 1 survey; 49\% were based in the United States of America (USA), 36\% in Asia-Pacific countries and 15\% in Europe. We incorporated comments gathered from round 1 and modified the survey in round 2 as follows: (1) addition of subcategories 'phakic' and 'pseudophakic' to the question 
'malignant glaucoma requiring surgical intervention', (2) addition of phakic status to the question 'tube lenticular touch', (3) addition of 'brisk' and 'minor' to describe types of wound leak. Results from round 1 available via the link https://www.enalyzer.com:443/reporting/sharedreport?key=fc579695-92c6-4fbf-820331a2edf98d73. We achieved a participation rate of $80.5 \%$ in round 2 . The median grades of severity of complications after round 2 are shown in Table 3 and Figures 2-4 Supplemental Material at AJO.com. All except one complication (tube-lenticular touch in a phakic eye) achieved good consensus. (Figures 2, 3, 4, Supplemental Material at AJO.com).

\section{DISCUSSION}

This study systematically assessed how complications of glaucoma surgery were analyzed and reported in recent RCTs. In addition, we have developed a classification system for severity of glaucoma surgical complications, based on consensus among international experts.

Using the CONSORT checklist for reporting of harm, our study showed that quality of reporting complications in RCTs involving glaucoma surgery is poor, as we observed that 10 out of 15 CONSORT criteria were reported in less than $50 \%$ of publications. This is consistent with poor quality of harm reporting among clinical trials in other health areas such as oncology, rheumatology and complementary medicine. ${ }^{11,56-58}$ The majority of glaucoma trials $(78.7 \%)$ reported frequency of complications but did not try to quantify their severity. It is likely that the lack of a validated, standardized instrument to report harm according to severity may have influenced this poor reporting to date. Inconsistency in defining severity among those studies that reported severe or major complications is another potential problem which makes comparisons of harm between different studies difficult (Table 2, Supplemental Material at AJO.com). This is in contrast when compared to only $12 \%$ of RCTs involving rheumatoid arthritis which failed to report severity of complications, as typically RCTs on interventions for rheumatoid arthritis report severity according to the validated WHO scale and the Common Terminology Criteria for Adverse Events v3.0 (CTCAE). ${ }^{56}$ On a positive note our review showed that most glaucoma RCTs described well the timing of collection of harm data, 
which constitute $93.6 \%$ of publications. ${ }^{56}$ This may be due to the stringent follow up protocol incorporated into glaucoma surgery trials. Our review also showed good reporting of denominators for adverse events (91.5\%) and balanced discussion of harms data (93.8\%). This echoed findings from another study by O'Day et $\mathrm{al}^{73}$ reviewing RCTs on intravitreal therapies for diabetic macula edema. A high proportion of their studies provided a balanced discussion of harms data (86\%). In their study, the two least commonly reported criteria were definition of adverse events (31\%) and withdrawal due to adverse events (36\%). In comparison, the least commonly reported criteria in our study were use of a validated instrument to report severity $(0 \%)$, withdrawal due to adverse events (6.4\%) and subgroup analyses of harm (6.4\%).

Quantifying the severity of complications after general surgery has been possible since the Clavier classification system in 1992 where complications were graded in five possible levels based on the level of intervention or therapy needed to address the complication .63 This effort was meant to increase transparency of reporting and provide an objective assessment method for assessing risks of different interventions. A further study validated an upgraded version of this classification system, with seven grades of severity, the Clavien-Dindo classification system. ${ }^{64}$ The acceptability and reproducibility of this classification system has also been confirmed through a survey of international experts within the field, and has been used for classifying complications related to liver transplantation. 65

The Delphi approach utilized in our study is an established method of generating consensus from a group of experts regarding a highly specialized topic, ${ }^{66}$ and it has been used widely in health care, e.g., in formulating policies and programs, identifying and measuring uncertainty, to explore issues in health services organizations, to develop criteria for appropriateness of clinical treatment, and to make long-term projections of need for patient care. ${ }^{67}$ The reproducibility of the Delphi method among panels of experts in a particular area of interest has been confirmed in several studies. 74-76 However, there is no absolute means for judging whether a decision is valid. The Delphi method among experts has been used to define a core event set of complications associated with arthroscopic rotator cuff repair. ${ }^{68} \mathrm{~A}$ Delphi survey has 
also been used to define outcome measures for glaucoma effectiveness trials, ${ }^{69}$ to ascertain specifications on screening intervention for open angle glaucoma ${ }^{70}$ and to develop standards for glaucoma virtual clinics in the UK. ${ }^{71}$ In our study, we aimed to rank expected glaucoma surgery complications according to severity. We achieved a high level of consensus in two rounds with a high response rate $(80 \%)$, which is a strength of this study. The sample size of our study is adequate as the survey targeted experts who have similar training and general understanding in the field of interest. ${ }^{66}$ One limitation of this study that we only reviewed trials published in English. Another limitation is that we did not attempt to validate this classification system with the patients' perspective. However, our classification on severity of complications created from the Delphi survey (Table 3 ) concurs with measures of severity from large, established RCTs. For example, the definition of severe complications adopted by the Ahmad Baerveldt Comparison (ABC) study and Tube versus Trabeculectomy (TVT) study was loss of least 2 lines of Snellen VA, which is equivalent to a severity score of 7 or 8 on the classification scale depending on the number of lines lost. Examples of 'severe complications' requiring return to theatre given by the TVT study included persistent corneal edema and hypotony maculopathy, both of which received a severity score of 8 on our scale.

We acknowledge that there is a variety of ways in which surgical complications can be defined but our study showed that experts agreed in quantifying their severity. For example, in a recent literature review on the reporting of hypotony after glaucoma surgery, the authors found that this parameter had been inconsistently defined across 128 studies. ${ }^{71}$ They have also concluded that hypotony should be further coded according to clinical significance. In our study, we have described hypotony as either 'early post-operative with no other symptoms', 'persistent low IOP with no other symptoms', 'low IOP and shallow anterior chamber with peripheral iris-corneal touch' or 'hypotony with maculopathy' to reflect the varying grades of severity. It is also possible that similar adverse events from different surgical procedures may not always have the same severity. For example, a shallow anterior chamber after a glaucoma drainage device that leads to tube-corneal touch may be perceived as a more severe complication than a similarly shallow anterior chamber after trabeculectomy. 
In conclusion, there is a need to improve the reporting of harm arising from glaucoma surgical RCTs. Rather than reporting only the frequency of complications we propose the use of a classification system of severity based on expert consensus to better compare the risks and benefits of different surgical interventions for glaucoma. We also recommend further efforts to validate this novel classification system including the involvement of patients' perspectives. 


\section{ACKNOWLEDGEMENT}

A) FUNDING/SUPPORT: This work is supported by the Wellcome Trust Institutional Strategic Support Fund (ISSF) awarded to Queen's University Belfast.

B) FINANCIAL DISCLOSURES: No financial disclosures

C) OTHER ACKNOWLEDGEMENTS: In work unrelated to this study, Dr. Pasquale is an advisory board member of Eyenovia and paid consultant for Bausch+Lomb. 


\section{$\underline{\text { References }}$}

1) Barton K, Feuer WJ, Budenz DL, et al. Three-year treatment outcomes in the Ahmed Baerveldt comparison study. Ophthalmology. 2014; 121:1547-57.

2) Budenz DL, Feuer WJ, Barton K, et al. Postoperative complications in the Ahmed Baerveldt comparison study during five years of follow-up. Am J Ophthalmol. 2016;163:75-82.

3) Gedde SJ, Herndon LW, Brandt JD, et al. Postoperative complications in the Tube Versus Trabeculectomy (TVT) study during five years of follow-up. Am J Ophthalmol 2012;153:804-814

4) Rahman MQ, Beard SM, Discombe R, et al. Direct healthcare costs of glaucoma treatment. Br J Ophthalmol. 2013; 97:720-4.

5) Krupski TL. Standardization of reporting surgical complications--are we ready? J Urol 2010; 183:1671

6) Breau RH, Gaboury I, Scales CD Jr, et al. Reporting of harm in randomized controlled trials published in the urological literature. J Urol. 2010; 183:1693-7. 7) Martin, RC 2nd, Brennan MF, Jaques DP. Quality of complication reporting in the surgical literature. Annals of Surgery, 2002; 235: 803-813.

8) loannidis JP, Lau J. Completeness of safety reporting in randomized trials: an evaluation of 7 medical areas. JAMA. 2001 24-31; 285:437-443.

9) Shaarawy T, Sherwood M, Grehn F (eds). Guidelines on design and reporting of glaucoma surgical trials issued by the World Glaucoma Association, Amsterdam: Kugler Publications, 2009: 35-40. 
10) loannidis J. CONSORT extension for better reporting of harm, in Guidelines for Reporting Health Research: A User's Manual (eds.: Moher D, Altman DG, Schulz KF, Simera I and Wager E), Oxford, UK: John Wiley \& Sons, Ltd,2014:93-100

11) Péron J, Maillet D, Gan $H$, et al. Adherence to CONSORT adverse event reporting guidelines in randomized clinical trials evaluating systemic cancer therapy: a systematic review, J Clin Oncol 2013; 31: 3957-3963.

12) Ang GS, Chan KC, Poostchi A, et al. Comparison of standard trabeculectomy versus microtrabeculectomy as a surgical treatment for glaucoma: a randomized clinical trial. Clin Exp Ophthalmol 2011; 39:648-657.

13) Arish $M$, Khallaghi $H$, Soltani $E$, Akbarpour R. A comparative study of sutureless scleral tunnel trabeculectomy versus conventional trabeculectomy in the management of primary open-angle glaucoma. International Ophthalmology. 2014; 34:1055-1059. 14) Pro Pro T, Mediking Company L. Ologen collagen matrix safety and effective comparison with mitomycin-C (MMC) in glaucoma surgery, 2010. Available at https://clinicaltrials. gov/ct2/show/NCT00538590 [accesed on 1/1/2018]

15) Jampel HD, Musch DC, Gillespie BW, et al. Collaborative Initial Glaucoma Treatment Study Group. Perioperative complications of trabeculectomy in the collaborative initial glaucoma treatment study (CIGTS). Am J Ophthalmol 2005; 140:1622.

16) Khairy $\mathrm{H}$, Elsawy M. Trabeculectomy with mitomycin-C versus trabeculectomy with amniotic membrane transplant: a medium-term randomized, controlled trial. J Glaucoma $2015 ; 24: 556-559$. 
17) Khairy H, Elsawy M, Said-Ahmed K. Sutureless scleral tunnel trabeculectomy: evaluation of feasibility and effectiveness versus conventional trabeculectomy for management of primary open angle glaucoma. Semin Ophthalmol. 2018;33:345-350. 18) Koval MS, Moster MR, Freidl KB, et al. Intracameral triamcinolone acetonide in glaucoma surgery: A prospective randomized controlled trial. Am J Ophthalmol. 2014; 158:395-401.

19) Papaconstantinou D, Georgalas I, Karmiris E, et al. Trabeculectomy with OloGen versus trabeculectomy for the treatment of glaucoma: a pilot study. Acta Ophthalmol 2010; 88:80-85.

20) Senthil S, Rao H, Babu J, Mandal A, Garudadri C. Comparison of outcomes of trabeculectomy with mitomycin C vs. ologen implant in primary glaucoma. Indian J Ophthalmol. 2013; 61:338-342.

21) Simsek T, Cankaya AB, Elgin U. Comparison of needle revision with subconjunctival bevacizumab and 5-fluorouracil injection of failed trabeculectomy blebs. J Ocul Pharmacol Ther. 2012; 28:542-546.

22) Suh W, Kee C. The effect of bevacizumab on the outcome of trabeculectomy with 5Fluorouracil. J Ocul Pharmacol Ther. 2013; 29:646-651.

23) Vandewalle E, Van de Veire S, Renier C, et al. Trabeculectomy with or without anterior chamber maintainer and adjustable sutures. J Glaucoma. 2014; 23:95-100. 24) Wasielica-Poslednik J, Hoffmann EM, Herzog D, Aliyeva S, Lamparter J, Pfeiffer N. The size of subconjunctival preparation does not influence the outcome of trabeculectomy with mitomycin C. J Glaucoma. 2015; 24:e75-79 
25) Zahid S, Musch DC, Niziol LM, Lichter PR, Collaborative Initial Glaucoma Treatment Study G. Risk of endophthalmitis and other long-term complications of trabeculectomy in the Collaborative Initial Glaucoma Treatment Study (CIGTS). Am J Ophthalmol. 2013; 155:674-680.

26) Barton K, Gedde S, Budenz D, Feuer W, Schiffman J. The Ahmed Baerveldt Comparison Study methodology, baseline patient characteristics, and intraoperative complications.Ophthalmology 2011; 118:435-442.

27) Budenz D, Barton K, Feuer W, et al. Treatment outcomes in the Ahmed Baerveldt Comparison Study after 1 year of follow-up. Ophthalmology 2011; 118:443-452.

28) Budenz D, Barton K, Gedde S, et al. Five-year treatment outcomes in the Ahmed Baerveldt comparison study. Ophthalmology. 2015; 122:308-316.

29) Christakis P, Kalenak J, Zurakowski D, et al. The Ahmed Versus Baerveldt study: one-year treatment outcomes. Ophthalmology. 2011; 118:2180-2189.

30) Christakis P, Tsai J, Zurakowski D, Kalenak J, Cantor L, Ahmed, II. The Ahmed Versus Baerveldt study: design, baseline patient characteristics, and intraoperative complications. Ophthalmology. 2011; 118:2172-2179.

31) Christakis PG, Kalenak JW, Tsai JC, et al. The Ahmed versus Baerveldt study: fiveyear treatment outcomes. Ophthalmology. 2016; 123:2093-2102.

32) Christakis PG, Tsai JC, Kalenak JW, et al. The Ahmed versus Baerveldt study: three-year treatment outcomes. Ophthalmology. 2013; 120:2232-2240.

33) Christakis PG, Zhang D, Budenz DL, et al. Five-year pooled data analysis of the Ahmed Baerveldt Comparison study and the Ahmed versus Baerveldt study. Am J Ophthalmol 2017; 176:118-126. 
34) Nassiri N, Kamali G, Rahnavardi M, et al. Ahmed glaucoma valve and single-plate Molteno implants in treatment of refractory glaucoma: a comparative study. $A m \mathrm{~J}$ Ophthalmol 2010; 149:893-902.

35) Pakravan M, Rad SS, Yazdani S, Ghahari E, Yaseri M. Effect of early treatment with aqueous suppressants on ahmed glaucoma valve implantation outcomes.

Ophthalmology 2014; 121:1693-1698.

36) Yuen D, Buys Y, Jin YP, Alasbali T, Smith M, Trope GE. Corticosteroids versus NSAIDs on intraocular pressure and the hypertensive phase after Ahmed glaucoma valve surgery. J Glaucoma 2011; 20:439-44.

37) Yazdani S, Mahboobipour H, Pakravan M, Doozandeh A, Ghahari E. Adjunctive Mitomycin $\mathrm{C}$ or Amniotic membrane transplantation for Ahmed glaucoma galve implantation: a randomized clinical trial. J Glaucoma. 2016; 25:415-21.

38) Dahan E, Ben Simon GJ, Lafuma A. Comparison of trabeculectomy and Ex-PRESS implantation in fellow eyes of the same patient: a prospective, randomised study. Eye. 2012; 26:703-710.

39) De Jong LA. The Ex-PRESS glaucoma shunt versus trabeculectomy in open-angle glaucoma: a prospective randomized study. Adv Ther. 2009;26:336-45 40) Gonzalez-Rodriguez JM, Trope GE, Drori-Wagschal L, Jinapriya D, Buys YM. Comparison of trabeculectomy versus Ex-PRESS: 3-year follow-up. Br J Ophthalmol $2016 ; 100: 1269-1273$.

41) Matlach J, Dhillon C, Hain J, Schlunck G, Grehn F, Klink T. Trabeculectomy versus canaloplasty (TVC study) in the treatment of patients with open-angle glaucoma: a prospective randomized clinical trial. Acta Ophthalmol. 2015; 93:753-761. 
42) Mendoza-Mendieta ME, Lopez-Venegas AP, Valdes-Casas G. Comparison between the Ex-PRESS P-50 implant and trabeculectomy in patients with open-angle glaucoma. Clinical Ophthalmol. 2016; 10:269-276.

43) Netland PA, Sarkisian Jr SR, Moster MR, et al. Randomized, prospective, comparative trial of Ex-PRESS glaucoma filtration device versus trabeculectomy (XVT Study). Am J Ophthalmol. 2014;157:433-440.

44) Wagschal LD, Trope GE, Jinapriya D, Jin YP, Buys YM. Prospective randomized study comparing Ex-PRESS to trabeculectomy: 1-Year Results. J Glaucoma. 2015; 24:624-9.

45) Dhalla K, Cousens S, Bowman R, Wood M, Murdoch I. Is beta radiation better than 5-flurouracil as an adjunct for trabeculectomy surgery when combined with cataract surgery? A randomised controlled trial. PLoS One. 2016;11:e0161674.

46) Hou X, Hu D, Cui Z, Zhou J, Cai L, Wang Y. Small-incision phacotrabeculectomy versus phacoemulsification in refractory acute primary angle closure with cataract. $B M C$ Ophthalmol. 2015; 15:88.

47) Liaska A, Papaconstantinou D, Georgalas I, Koutsandrea C, Theodosiadis P, Chatzistefanou K. Phaco-trabeculectomy in controlled, advanced, open-angle glaucoma and cataract: parallel, randomized clinical study of efficacy and safety. Semin Ophthalmol. 2014;29:226-235.

48) Nassiri N, Nassiri N, Mohammadi B, Rahmani L. Comparison of 2 surgical techniques in phacotrabeculectomy: 1 site versus 2 sites. Eur J Ophthalmol 2010; 20:316-326. 
49) Sengupta S, Venkatesh R, Ravindran RD. Safety and efficacy of using off-label bevacizumab versus mitomycin $\mathrm{c}$ to prevent bleb failure in a single-site phacotrabeculectomy by a randomized controlled clinical trial. J Glaucoma. 2012; 21:450-459.

50) Tham C, Kwong Y, Leung D, et al. Phacoemulsification vs phacotrabeculectomy in chronic angle-closure glaucoma with cataract: complications. Arch Ophthalmol 2010; 128:303-311.

51) Skaat, A., Sagiv, O, Kinori, M, Simon, G, Goldenfeld, M, Melamed, S Gold microshunt implants versus Ahmed glaucoma valve: long-term outcomes of a prospective randomized clinical trial. J Glaucoma 2016; 25:155-161.

52) Zahid S, Musch DC, Niziol LM, Lichter PR, Collaborative Initial Glaucoma Treatment Study G. Risk of endophthalmitis and other long-term complications of trabeculectomy in the Collaborative Initial Glaucoma Treatment Study (CIGTS). Am J Ophthalmol. $2013 ; 155: 674-680$

53) Zhang M, Li B, Sun Y. Ex-PRESS and Ahmed glaucoma valve in treatment of refractory glaucoma. Acta Ophthalmol. 2016;94:e382-e383.

54) El-Saied HM, Abdelhakim MASE. Different surgical modalities for management of glaucoma after silicone oil removal in vitrectomized eyes: One Year Comparative Study. Retina. 2017; 37:1535-1543

55) Rekas M, Byszewska A, Petz K, Wierzbowska J, Junemann A. Canaloplasty versus non-penetrating deep sclerectomy - a prospective, randomised study of the safety and efficacy of combined cataract and glaucoma surgery; 12-month follow-up. Graefes Arch Clin Exp Ophthalmol. 2015;253:591-599. 
56) Hadi MA, McHugh GA, Conaghan PG. Quality of reporting of harm in randomised controlled trials of pharmacological interventions for rheumatoid arthritis: a systematic review, Evid Based Med 2017; 22:170-177.

57) Smith SM, Chang RD, Pereira A, et al. Adherence to CONSORT harm-reporting recommendations in publications of recent analgesic clinical trials: an ACTTION systematic review. Pain 2012;153:2415-21

58) Turner LA, Singh K, Garritty C, et al. An evaluation of the completeness of safety reporting in reports of complementary and alternative medicine trials. BMC Complement Altern Med 2011;11:67. https://bmccomplementalternmed.biomedcentral.com/track/pdf/ 10.1186/1472-6882-11-67. Assessed Feb 1, 2018

59) Lineberry N, Berlin JA, Mansi B et al. Recommendations to improve adverse event reporting in clinical trial publications: a joint pharmaceutical industry/journal editor perspective. BMJ. 2016 3;355:i5078.

60) Battisti WP, Wager E, Baltzer L, et al. International Society for Medical Publication Professionals. Good publication practice for communicating company-sponsored medical research: GPP3. Ann Intern Med 2015;163:461-464.

61) Breusegem C, Spielberg L, Van Ginderdeuren R, Vandewalle E, Renier C, Van de Veire S, et al. Preoperative nonsteroidal anti-inflammatory drug or steroid and outcomes after trabeculectomy: a randomized controlled trial. Ophthalmology. 2 010; 117:1324-30. 62) Grieshaber MC, Pienaar A, Olivier J, Stegmann R. Canaloplasty for primary openangle glaucoma: long-term outcome. Br J Ophthalmol. 2010; 94:1478-82.

63) Clavien PA, Sanabria JR, Strasberg SM. Proposed classification of complications of surgery with examples of utility in cholecystectomy. Surgery. 1992; 111:518 -526 
64) Clavien PA, Barkun J, de Oliveira ML, et al. The Clavien-Dindo classification of surgical complications: five-year experience. Ann Surg. 2009; 250:187-96.

65) Tamura S, Sugawara Y, Kaneko J et al. Systematic grading of surgical complications in live liver donors according to Clavien's system. Transpl Int 2006; 19:982-987.

66) Chia-Chien H, Sandford BA. The Delphi technique: making sense of consensus. Practical Assessment, Research and Evaluation. 2007; 12:1-8 http://pareonline.net/pdf/v12n10.pdf. Assessed Dec21,2017

67) Akins RB, Tolson H, Cole BR. Stability of response characteristics of a Delphi panel: application of bootstrap data expansion. BMC Med Res Methodol. 2005 1;5:37. 68) Audigé L, Flury M, Müller AM, ARCR CES Consensus Panel, Durchholz H. Complications associated with arthroscopic rotator cuff tear repair: definition of a core event set by Delphi consensus process. J Shoulder Elbow Surg. 2016; 25:1907-1917. 69) Ismail R, Azuara-Blanco A, Ramsay CR. Consensus on outcome measures for glaucoma effectiveness trials: results from a Delphi and nominal group technique approaches. J Glaucoma. 2016;25:539-46.

70) Campbell SE, Azuara-Blanco A, Campbell MK, et al. Developing the specifications of an open angle glaucoma screening intervention in the United Kingdom: a Delphi approach. BMC Health Serv Res. 2012 5;12:447.

https://bmchealthservres.biomedcentral.com/articles/10.1186/1472-6963-12-447.

Assessed Feb 7, 2018. 
71) Kotecha A, Longstaff S, Azuara-Blanco A, et al. Developing standards for the development of glaucoma virtual clinics using a modified Delphi approach. $\mathrm{Br} \mathrm{J}$ Ophthalmol. 2018; 102: 531-534.

72) Abbas A, Agrawal P, King AJ. Exploring literature-based definitions of hypotony following glaucoma filtration surgery and the impact on clinical outcomes. Acta Ophthalmol 2018; 96(3):e285-e289. .

73) O'Day R, Walton R, Blennerhassett R, Gillies MC, Barthelmes D. Reporting of harms by randomised controlled trials in ophthalmology. Br J Ophthalmol. 2014; 98:1003-8.

74) Kastein MR, Jacobs M, Van der Hell RH, Littick K, Touw-Otten FWMM. Delphi, the issue of reliability: a qualitative Delphi study in primary health care in the Netherlands. Technol Forecasting Soc Change; 1993; 44:315-23.

75) Duffied C. The Delphi technique: a comparison of results obtained using two expert panels. Int J Nur Stud; 1993; 30:227-37.

76) Murphy MK, Black NA, Lamping DL, et al. Consensus development methods, and their use in clinical guideline development. Health Technol Assess. 1998; 2:i-iv, 1-88. 


\section{Legends}

Figure 1. PRISMA flowchart showing number of glaucoma surgical trials identified and selected

Figure 2. General complications of glaucoma surgery graded according to severity (from 1 to 10 ) by glaucoma experts: median and interquartile range (IQR)

Figure 3. Complications specific to glaucoma aqueous shunts graded according to severity (from 1 to 10 ) by glaucoma experts: median and interquartile range (IQR) Figure 4. Complications specific to trabeculectomy graded according to severity (from 1 to 10$)$ by glaucoma experts: median and interquartile range (IQR) 